\title{
Risk aversion and optimal management of an uneven-aged forest under risk of windthrow: A Markov decision process approach
}

\author{
Stéphane Couture*, Marie-Josée Cros, Régis Sabbadin \\ INRA, UR 875 Applied Mathematics and Computer Science Laboratory (MIAT), 24 Chemin de Borde Rouge, \\ Auzeville CS 52627, 31326 Castanet Tolosan cedex, France
}

\section{A R T I C L E I N F O}

\section{Article history:}

Received 29 December 2014

Accepted 20 August 2016

\section{Keywords:}

Forest management

Uneven-aged forestry

Climate change

Optimal harvesting

Single species stand

MDP

\begin{abstract}
A B S T R A C T
Forests are increasingly threatened by windthrows but those composed of uneven-aged stand plots are generally less impacted by their effects. As a consequence, the management of such forests should be based on a joint management of all their different uneven-aged stand plots. This article determines the optimal management regime of uneven-aged forests under risk of windthrow and furthermore takes the risk preferences of the forest owner into account. This study analyzes optimal harvesting of uneven-aged stand plots by applying a Markov decision process (MDP) framework using an economic description of uneven-aged forestry. Two management types are considered: the joint uneven-aged forest management model in which the forest owner jointly manages all the different stand plots, and the independent uneven-aged forest management model that assumes that the forest owner independently manages each plot of the forest. The MDP framework is applied to a non-industrial private forest owner located in northeastern France. First, we show that the forest owner tends to converge toward a forest structure that is close to a normal forest in the joint uneven-aged forest management model. Second, we find that the independent uneven-aged forest management model poorly approximates the optimal multi-stand harvesting policy. Third, and more surprisingly, the levels of windthrow probability
\end{abstract}

\footnotetext{
* Corresponding author. Fax: +33561285335.

E-mail address: stephane.couture@toulouse.inra.fr (S. Couture).
} 
changes considered have little influence on the optimal harvesting strategies of the forest owner. Lastly, in contrast, the forest owner's risk aversion is shown to have a strong influence on the optimal policy.

(c) 2016 Department of Forest Economics, Swedish University of Agricultural Sciences, Umeå. Published by Elsevier GmbH. All rights reserved.

\section{Introduction}

Uneven-aged forests are generally more resistant to natural disasters such as windthrow because of a higher stability against storm damage (Mason, 2002; Hanewinkel et al., 2014) in comparison with even-aged forests. Furthermore, the frequency and intensity of windthrows are projected to increase due to climate change (Haarsma et al., 2013), requiring changes in forest management plans and practices (FAO, 2013). This supports the application of uneven-aged forest management. The unevenaged forest system has a long tradition in Central Europe (Rollin et al., 2005; O'Hara et al., 2007; Puettmann et al., 2015) but has always been applied to just a small portion of the total forest area (Boncina, 2011). This type of forest management can be difficult to carry out for many private forest owners. It is therefore important to study to what extent uneven-aged forest management can be adapted to respond to the increase in windthrow risk. While forest management under windthrow, mainly dealing with even-aged forests, has received considerable attention in the literature over the last decades (Loisel, 2014), empirical analysis and modeling studies on windthrow damage in unevenaged forests are less frequent (Hanewinkel et al., 2014).

Before analyzing uneven-aged forest management, it can be difficult to assess precisely windthrow risk and its potential variation due to climate change. Future climate evolution and its impact on forest ecosystems are not easily evaluated in terms of standard probability concepts (Schou et al., 2015). Since the probabilities of catastrophic events might increase, exploring the consequences of different values of probabilities allows us to investigate how the forest owner's optimal decision concerning forest management is affected by uncertain climate change. Although risks of extreme events have a large impact on forest management, forest owners' decisions also depend on their risk attitudes. Indeed, behavior under risk typically results from the interplay of the risk level faced by forest owners (level of probability) and their perception of risk. Forest owners' risk preferences are key factors in explaining variability in behavior between decision-makers. Risk attitude is the stance a forest owner has towards the content and the consequences of risk (attitudes towards risk can be risk-averse, risk-neutral or risk-seeking). It is the interaction between risk perception and risk attitudes that matters in decisionmaking. There is no doubt that many forest owners are not risk-neutral but risk-averse instead, and forest owners' risk preferences have a significant impact on forest management (Andersson and Gong, 2010; Brunette et al., 2014). It is therefore essential to consider risk and risk aversion when addressing the problem of forest management.

As indicated by Schou et al. (2015), reviews of decision-making under climate change (Yousefpour et al., 2012) and of the modeling of natural hazards in forest management (Hanewinkel et al., 2011) present a comprehensive overview of the literature on decision making under uncertainty. In the same way, Pasalodos-Tato et al. (2013) reviewed and classified methods and approaches to deal with risk and uncertainty in forest planning. They classified methods including risk and uncertainty models into different categories depending on the spatial scale of the planning problem addressed (stand level, forest/landscape level and regional level). In contrast we only focus on studies based on Markov chains in order to describe the similarities and differences with our study. Since forest management can be modeled as a controlled Markov process (Lohmander, 2011), the Markov decision process ${ }^{1}$ is a technique commonly used to deal with risk and uncertainty at the stand level (Hool, 1966; Lembersky

1 Williams (2009) presents a general review of MDP applications in natural resources management. 
and Johnson, 1975; Kao, 1982; Teeter and Caulfield, 1991; Pastor et al., 2005; Lin and Buongiorno, 1998; Kaya and Buongiorno, 1987; Rollin et al., 2005; Buongiorno and Zhou, 2011; Zhou and Buongiorno, 2011) as well as at the forest level when addressing spatial problems (Spring et al., 2005a; Sabbadin et al., 2007; Forsell et al., 2011). However, the current literature concerning the MDP model only considers risk-neutral forest owners.

It is recognized that forest owners are generally risk averse (Brunette et al., 2014). The impact of risk aversion on the forest owner's behavior has been demonstrated in different models (Ollikainen, 1993; Gong, 1998; Lönnstedt and Svensson, 2000; Gong and Löfgren, 2003; Alvarez and Koskela, 2006; Andersson, 2012). For example, in a Wicksellian single rotation framework, Alvarez and Koskela (2006) indicate that higher risk aversion decreases the optimal harvesting threshold and thus shortens the expected rotation period. In the same way, in an expected utility maximization model, Gong (1998) shows that a risk-averse forest owner should harvest earlier than a risk-neutral one. In a multi-age class model, Tahvonen and Kallio (2006) (in a more general model that also includes forest owners' consumption-saving decision-making), and Salo and Tahvonen (2003) show that under strictly concave utility, it is optimal to adjust the age class structure close to a normal forest distribution (where the land is evenly allocated among the number of age classes).

Under climate change, forest owners are investigating new forest management strategies, especially by promoting uneven-aged forests. Uniform stand structure is considered to be an effective management option to reduce forest vulnerability. Mixing age classes has been proposed as one way to mitigate uncertainty. The forest planning literature has provided methods based on linear programming and optimal control models, as well as search algorithms to handle this problem (Adams and Ek, 1974; Berck, 1979; Johansson and Löfgren, 1985; Lyon and Sedjo, 1983; Sedjo and Lyon, 1990; Mitra and Wan, 1985; Salo and Tahvonen, 2002, 2003, 2004; Tahvonen, 2004; Tahvonen and Kallio, 2006; Couture and Reynaud, 2007; Goetz et al., 2013). In the long-run, it is optimal to let the forest evolve toward a normal forest structure. The main question is therefore whether or not the optimal solution converges to the normal forest age-class distribution. Such a question has never been tackled using an MDP model especially in the case of an explicit representation of risk aversion. ${ }^{2}$ Studying this problem within the MDP framework has several advantages. First, an MDP model does not simply provide an optimal decision path for an initial stand state but optimal decision rules that give optimal harvesting decisions for all possible states of the forest. Thus, while Faustmann rules can be represented in the MDP framework, original and more efficient management rules may result from the optimization. Second, we use the MDP framework to explicitly model the influence of risk and risk aversion on the optimal management policies in the context of multiple stand management. Indeed, there currently exist standard approaches for introducing risk aversion in MDP models such as the discounted expected utility framework frequently used in economics but never applied to uneven-aged forest management problem under risk aversion. With such an approach, dynamic programming can be used to efficiently compute an optimal policy with respect to the expected utility. This too is original, as is the simplified multi-stand model we propose and evaluate. Finally, the MDP framework has been extensively studied in the Artificial Intelligence literature in recent years, and several extensions of this model have also been studied, in particular ones that consider explicit interactions between independent processes (Forsell et al., 2011). Taking advantage of these advanced works to study risk aversion and forest management diversification at the same time is interesting to complement current research.

In this paper, we analyze optimal forest harvesting including multiple age classes, and forest owners' risk aversion. The problem of the forest owner is to manage a forest composed of different stand plots with different age classes in the presence of windthrow risk. We adopt an infinite-horizon stationary MDP framework to model this problem. We consider two management types: the joint uneven-aged forest management model in which the forest owner jointly manages all the different stand plots, and the independent uneven-aged forest management model that assumes that the forest owner independently manages each plot of the forest. In the joint uneven-aged forest management

\footnotetext{
2 Brunette et al. (2015) have adopted an MDP framework to analyze the impact of risk aversion on harvesting but they do not consider a classical and explicit multiple tree age class model.
} 
model, sylvicultural practices on each stand are decided on the basis of the observation of the state of all stands. On the other hand, in the independent uneven-aged model, sylvicultural practices on a given stand are decided on the basis of the state of this stand only. In other words, the forest owner may adopt forest-level management or stand-level management. Therefore, the independent unevenaged model is an even-aged management model. Note that, in this case, even though each stand is in a different initial condition, the optimal policy is the same for all stands. So all stands will converge sooner or later to the same steady state distribution. Independent management does not explicitly consider the possibility of mixing age classes in different stands, although windthrow may induce a diversification of age classes at the forest level. On the other hand, in the joint management problem, the forest owner can explicitly decide to manage risk damage by diversifying age classes at the forest level. The joint model may therefore make it possible to induce a "diversification effect" linked to risk aversion. The MDP framework allows to measure this effect. The framework we propose generalizes existing MDP studies that assume a single stand and risk neutrality.

We applied the MDP framework to a non-industrial private forest owner located in northeastern France. We show that the forest owner tends to converge toward a forest structure close to a normal forest where only the oldest tree age class is harvested in the joint uneven-aged forest management model. In the long-run equilibrium, the areas allocated to the different age classes are almost identical, except for the oldest age class for which the allocated area is reduced. We find that the independent uneven-aged forest management model is relatively inconsistent with the optimal multi-stand harvesting policy. More surprisingly, the plausible levels of windthrow probability changes that could result from climate change have little influence on the optimal harvesting strategies of the forest owner. In contrast, the forest owner's risk aversion has a strong influence on the optimal policy. The rest of the paper is organized as follows. In Section "The model", we describe the forest management model and we present the Markov decision process model. Section "Case study: model calibration and solution method" deals with the numerical approach for solving the model calibrated for a nonindustrial private forest owner located in northeastern France. In Section "Case study: results and discussion", we present the results of the application. We conclude with a brief summary of our findings in Section "Conclusion".

\section{The model}

We considered a non-industrial private forest owner facing a dynamic problem of forest management under storm risk over an infinity of harvesting periods. ${ }^{3}$ We assumed that the private forest owner manages a forest composed of different stand plots with one unique species. Let $n$ denote the number of stand plots. Each stand plot $i(i=1, \ldots, n)$ has trees of age $s_{i}$. Let us assume that $s_{i} \in\{1, \ldots$, $m$ \} with 1 coding the youngest age class and $m$ coding the oldest one. $m$ is the age after which trees no longer improve their value. Trees in age class $s_{i}$ are characterized by their timber content, $v_{s_{i}}$, measured in $\mathrm{m}^{3} / \mathrm{ha}$, and which increases with the age class, $v_{s_{i}} \geq v_{s_{i-1}}, \quad \forall 2 \leq s_{i} \leq m$. The Markov decision processes (MDP) framework allows us to efficiently model and solve this sequential decision-making problem under uncertainty (Sigaud and Buffet, 2010; Puterman, 1994). In its classical formulation, an infinite-horizon stationary MDP is described by a four-tuple, $\langle S, A, p, r\rangle$, where $S$ represents the finite set of states that can be reached by the system, $A$ represents the finite set of decisions that can be applied at each period, $p$ is a state transition function, and $r$ is a reward function.

\section{State and action variables}

The states of the $n$ stand plots of the forest are represented by the vector $s=\left(s_{1}, \ldots, s_{n}\right)$ where $s_{i} \in\{1, \ldots, m\}$ is the age class of stand plot $i$. The space of states, $S$, is then defined by $S=\{1, \ldots, m\}^{n}$. In each period, the forest manager has to decide on the number of stand plots of each tree age class to be harvested. The decision for each stand is either to do nothing or to cut the stand and reforest

\footnotetext{
${ }^{3}$ When the horizon is infinite, it can be shown that the value function of a stationary policy does not depend on time. For that reason, the time index does not appear in mathematical equations.
} 
immediately. Therefore, an action $a$ is represented as a vector of decisions $a=\left(a_{1}, \ldots, a_{n}\right)$ where $a_{i} \in\{1$, 2 ) with $a_{i}=1$ if the stand plot $i$ is not cut and $a_{i}=2$ if the stand plot $i$ is harvested. The space of actions, $A$, is defined by $A=\{1,2\}^{n}$.

Risk

The stochastic environment of the forest owner is described by a risk of stand plot destruction due to windthrow, depending on the age class of the stand alone, as suggested by Dhote (2000). We assume that windthrow may happen after harvests. Let $p_{s}$ denote the probability of a windthrow occurring within a period of time. Given a strong wind occurrence, trees may or may not be destroyed. $p d_{s_{i}}$ denotes the conditional probability of overturning a stand $i$ of age class $s_{i} \in\{1, \ldots, m\}$ given strong wind occurrence. Given strong wind occurrence, the probabilities of each stand being overturned are assumed to be independent for the purpose of simplification. ${ }^{4}$

\section{Returns}

Empirical evidence (Schelhaas et al., 2003) suggests that in the case of strong windthrow, the entire production is not lost. Hence, we assume that in the event of an age class destruction, a proportion $\alpha \in$ $[0,1]$ of the timber content can be recovered and sold by the forest-owner. This proportion corresponds to the percentage of salvage timber. $\alpha$ equal to 1 means that strong winds do not result in any timber losses and the only impact of the stochastic event is to impose harvesting at a time that may not be optimal. On the contrary, $\alpha$ equal to 0 means that a destroyed stand yields no revenue. The gross net revenue $w$ generated at each time period is the sum of net revenues of all plots: $w=\sum_{i=1}^{n} w_{i}$. The net revenue of each plot depends on the age of the plot, the decision to harvest and the occurrence of windthrow. The net revenue of the plot $i$ if harvested is: area $_{i}\left[v_{s_{i}}\left(T_{s_{i}}-C_{h}\right)-C_{p}\right]$ where area $_{i}$ is the area allocated to the plot $i, T_{S_{i}}$ represents the timber price (in $€ / \mathrm{m}^{3}$ ) for age class $s_{i}, C_{h}$ is the harvesting cost (in $€ / \mathrm{m}^{3}$ ), and $C_{p}$ is the planting cost (in $€ /$ ha). The harvesting cost is a function of the volume of timber harvested, thus of the age of the harvested plot. On the other hand, the planting cost is only a function of the area of the plot. The net revenue of the plot $i$ if not harvested and impacted by a storm is: area $_{i}\left[v_{s_{i}}\left(\alpha \cdot T_{s_{i}}-C_{r}\right)-C_{p}\right]$ where $C_{r}$ is the recovery cost in the case that the stochastic event occurs. The planting cost depends on the planted area and the harvesting and the recovery costs depend on the timber content. The net revenue is null for the other cases.

\section{Taking risk-aversion into account}

In a risk-neutral approach to decision under uncertainty, the utility of a policy is measured by the sum over time of expected rewards. There exist several ways to take risk-aversion into account in MDP models (discounted expected utility, risk sensitive average criterion, average value at risk). All of them correspond to replacing the expectation of a random variable over rewards with a lower value, reflecting the uncertainty "spread" of the distribution. One can, for example, apply a concave transformation to the reward, thus resulting in moving the random variable realizations to lower values (Fig. 1, top-right). Such an approach is currently used in economics for considering risk aversion into dynamic decision model under risk because it allows to represent different levels of risk aversion with a utility function representing the preference to riskiness by enforcing that an undesirable outcome has a low value of utility (Eeckhoudt et al., 2005). Other approaches keep the reward function unchanged, but penalize the expectation by a quantity related to the variance of the distribution: risk sensitive approaches (Coraluppi and Marcus, 1999; Alanis-Duran and Cavazos-Cadena, 2012) (Fig. 1, bottom left). Other approaches, such as the Average Value At Risk approach (Ruszczynski, 2010) (Fig. 1, bottom right) compute an aggregation index focused on the left part of the reward distribution. All these approaches are quite similar in the way they modify the expected reward criterion. In the following,

\footnotetext{
${ }^{4}$ We do not consider the interaction between plots and the explicit spatial links between them in our model. It is clear that this can be an important point of forest management (see Pasalodos-Tato et al., 2013).
} 

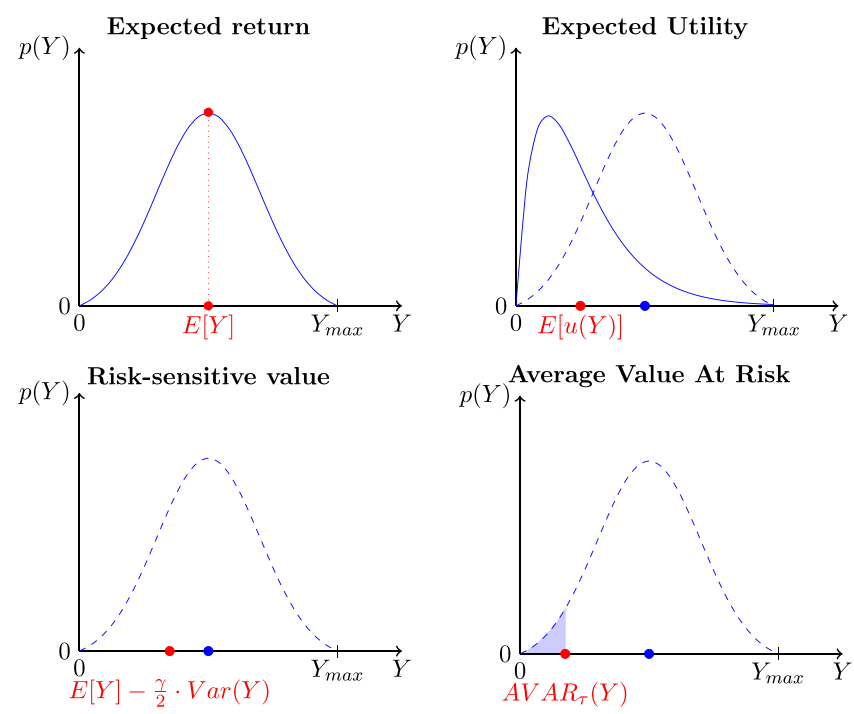

Fig. 1. Parameterized distortions of the expected value of a distribution over returns. Upper left: Expected return. Upper right: Expectation of a concave transformation of return $(u$ ). Lower left: Risk sensitive value (parameter $\rho$ ). Lower right: Average value at risk (parameter $\tau$ ).

we consider the expected utility criterion. This is currently used in forest economics to describe the behavior of a private forest owner under risk (Yousefpour et al., 2012).

The problem of the forest owner is to maximize the expected utility of the net revenue of timber harvest $w$. Assume, in addition, that the instantaneous utility is given by $U(w)$, where $U$ is a continuous, twice differentiable, increasing and strictly concave utility function. To take risk behavior into account in numerical computations, we apply the specification $U(w)=w^{1-\beta} /(1-\beta)$ if $w>0$, and $U(w)=$ $-(-w)^{1-\beta} /(1-\beta)$ if $w<0$, with $\beta \neq 1$. This utility function belongs to the Hyperbolic Absolute Risk Aversion family (Eeckhoudt et al., 2005). Parameter $\beta$ is the real value of the relative risk aversion coefficient. Therefore the reward function $r$ of the forest is equal to $r=U(w)$.

\section{Markov chain models of forest growth}

In the MDP framework, forest growth is described by the transition probabilities between forest states. The application of an action may change the state of the forest. Furthermore, the state of the forest at the next period depends stochastically only on the state of the forest at the current period and on the decision applied. The transition probabilities between forest states $p\left(s^{\prime} \mid s, a\right)$ are defined as the probability that the system will change from state $s$ to state $s^{\prime}$, given that action $a$ has been applied.

\section{The joint uneven-aged forest management model}

In the joint uneven-aged forest management model, the forest owner manages all the different stand plots simultaneously. In this case, the state transition function is defined as:

$$
p\left(s^{\prime} \mid s, a\right)=\sum_{\epsilon \in\{0,1\}} \prod_{i=1}^{n} p\left(s_{i}^{\prime} \mid s_{i}, a_{i}, \epsilon\right) p(\epsilon) .
$$

$\epsilon$ is a binary variable describing storm occurrence: $\epsilon=1$ if there is a storm and $\epsilon=0$ if there is no storm. The storm probability is defined by $p(\epsilon=1)=p_{s}$ and $p(\epsilon=0)=1-p_{s} \cdot p\left(s_{i}^{\prime} \mid s_{i}, a_{i}, \epsilon\right)$ is the probability that the stand plot $i$ 's age class changes from $s_{i}$ to $s_{i}^{\prime}$ under action $a_{i}$, given storm event $\epsilon$.

This transition probability is defined as follows: 
- If the chosen action is to cut the stand plot $\left(a_{i}=2\right)$, then the next state is $s_{i}^{\prime}=1$, regardless of the state $s_{i}$ and whether or not a storm occurs.

- If the chosen action is to let the stand plot grow, and there is no storm $(\epsilon=0)$, then trees will grow, for sure, leading to $s_{i}^{\prime}=\min \left\{s_{i}+1, m\right\}$.

- Finally, if the chosen action is to let the stand plot grow, and a storm occurs $(\epsilon=1)$, stand plot $i$ will be overturned, with probability $p_{d_{s_{i}}}$, reaching state $s_{i}^{\prime}=1$, or will grow with probability $1-p_{d_{s_{i}}}$, reaching state $s_{i}^{\prime}=\min \left\{s_{i}+1, m\right\}$.

In the joint transition model, we do not consider explicit relationships between stand plots (such as shelter provided by one stand plot to a neighborings stand plot). However, the model makes it possible to represent correlations between windthrow in all stand plots, through parameter $\epsilon$. The above model is a Markov decision process, with state and action space sizes $|S|=m^{n}$ and $|A|=2^{n}$. The explicit representation of transition probabilities by matrices therefore requires space $O\left(m^{2 n} .2^{n}\right)$, which becomes prohibitive when the number of stands, $n$, is large.

An optimal policy of the MDP, $\pi^{*}: S \rightarrow A$, can be obtained from the following equations:

$$
\pi^{*}(s)=\arg \max _{a}\left\{\sum_{s^{\prime}} p\left(s^{\prime} \mid s, a\right)\left(r\left(s, a, s^{\prime}\right)+\gamma V^{*}\left(s^{\prime}\right)\right)\right\}, \quad \forall s \in S,
$$

where $V^{*}$ is the unique fixed-point solution of the system of Bellman equations (Puterman, 1994):

$$
V(s)=\max _{a}\left\{\sum_{s^{\prime}} p\left(s^{\prime} \mid s, a\right)\left(r\left(s, a, s^{\prime}\right)+\gamma V\left(s^{\prime}\right)\right)\right\}, \quad \forall s \in S .
$$

An optimal policy $\pi^{*}: S \rightarrow A$ is a state-dependent rule that gives the best action $\pi^{*}(s) \in A$ to take in state $s . V^{*}($.$) is the value function of the optimal policy. \gamma$ is the discount factor, and $r\left(s, a, s^{\prime}\right)=$ $\sum_{i=1}^{n} r_{i}\left(s_{i}, a_{i}, s_{i}^{\prime}\right)$ is the instant reward.

The independent uneven-aged forest management model

In the independent uneven-aged forest management model, we assume that the forest owner independently manages each plot of the forest. In this case, the state transition function $p\left(s^{\prime} \mid s, a\right)$ defined in Eq. (1) is approximated by the following factored transition function $p^{I}\left(s^{\prime} \mid s, a\right)$ :

$$
p^{I}\left(s^{\prime} \mid s, a\right)=\prod_{i=1}^{n} p^{I}\left(s_{i}^{\prime} \mid s_{i}, a_{i}\right)
$$

with $p^{I}\left(s_{i}^{\prime} \mid s_{i}, a_{i}\right)=\sum_{\epsilon_{i} \in\{0,1\}} p\left(s_{i}^{\prime} \mid s_{i}, a_{i}, \epsilon_{i}\right) p\left(\epsilon_{i}\right)$. Intuitively, with Eq. (4), it is assumed that "independent" storm events occur independently in each stand. Thus, all correlations between windthrow in various stands are now lost. This is, of course, unrealistic. However, this assumption is a very natural way to be able to efficiently compute approximate management policies, even for problems with many stands. Therefore, we empirically evaluate independent management against joint management in this study, to test whether the loss in the expected present value incurred by applying independent management is reasonable or not. A positive answer would mean that the search for management policies can be restricted to independent ones, which would be both simpler to compute and easier to represent.

The factored transition function $p^{I}\left(s^{\prime} \mid s, a\right)$ is an approximation of the transition function $p\left(s^{\prime} \mid s, a\right)$. The infinite-horizon stationary MDP corresponding to this approximation is described by the fourtuple, $\left\langle S, A, p^{I}, r>\right.$. It is easy to prove that the optimal policy of this MDP, $\pi^{I^{*}}$, can be obtained by solving $n$ independent and identical MDPs described by the four-tuple $\left\langle\{1, \ldots, m\},\{1,2\}, p^{I}, r\right\rangle$. The policy $\pi^{*^{*}}$ is then an approximation of the optimal policy $\pi^{*}$ of the joint model. This policy has a double advantage: first, it can be concisely represented using the solution policies $\pi_{i}^{*}\left(s_{i}\right)$ of the independent MDPs and second these policies are identical, and can be obtained by solving a single MDP with sizes of the state 
Table 1

Characteristics of tree age classes.

\begin{tabular}{lllll}
\hline Age class $s_{i}$ & $\begin{array}{l}\text { Age interval of the } \\
\text { period (years) }\end{array}$ & $\begin{array}{l}\text { Timber content } v_{s_{i}}{ }^{\mathrm{a}} \\
\mathrm{m}^{3} / \mathrm{ha}\end{array}$ & $\begin{array}{l}\text { Timber price } T_{s_{i}}{ }^{\mathrm{b}} \\
\left(10^{3} € / \mathrm{m}^{3}\right)\end{array}$ & $\begin{array}{l}\text { Conditional probability } \\
\text { of overturning }\end{array}$ \\
\hline 1 & {$[0,20]$} & 24.60 & 0.1303 & 1 \\
2 & {$[20,40]$} & 112.20 & 1.3688 & 30 \\
3 & {$[40,60]$} & 353.50 & 8.4133 & 65 \\
4 & {$[60,80]$} & 601.40 & 22.0713 & 71 \\
5 & {$[80, \infty[$} & 694.70 & 30.9836 & 72 \\
\hline
\end{tabular}

a Adapted from Vannière (1984).

b From Guo (1994).

c Using Picard et al. (2002) and based on interviews with forest experts.

and action state spaces equal to $m$ and 2, respectively. However, in general, $\pi^{I^{*}}$ is suboptimal in the original joint model.

\section{Case study: model calibration and solution method}

\section{Calibration of the model}

The model has been calibrated to represent the behavior of a non-industrial private forest-owner in Lorraine, a region located in northeastern France. The private forest estate is assumed to produce Norway spruce (Picea abies), one of the most common species found in Lorraine. With 25 million cubic meters on the ground, Lorraine was the second French region the most devastated by the exceptional storms of December 1999. Consistent with Tahvonen and Kallio (2006), we consider five tree age classes, $m=5$. Given the growth process of spruce, the time period represents a 20 -year interval. The volume per ha and the price for each age class for spruce in northeastern France are presented in Table 1.

The cost functions associated with forest management (planting, harvesting and recovery costs) are assumed to be linear and are derived from Guo (1994). The unit costs of planting, harvesting and recovering tree plots are $2103.8 € / \mathrm{ha}, 3.7$ and $5.5 € / \mathrm{m}^{3}$, respectively. In the case of the stochastic event occurring, it is assumed that $10 \%$ of the forest area can be recovered and sold ( $\alpha$ is equal to 0.1 ). The discount rate is assumed to be $0.1 \%$ per year. ${ }^{5}$ According to Picard et al. (2002) and the experts, the annual probability of strong wind occurrence is 0.0032 for the selected region. Assuming that strong wind occurrences are i.i.d., the probability of observing at least one strong wind during a 20-year period is equal to $p_{s}=6.2 \%$. As suggested by Dhote (2000), the conditional probabilities of overturning for age class $s_{i}$ given strong wind occurrence vary from $1 \%$ for the first age class to $72 \%$ for the fifth (see Table 1). We normalized the area of a forest plot to 1 ha. This reflects the French situation since approximately $68 \%$ of non-industrial private forest owners own less than one hectare. This assumption is not restrictive and larger forest areas may be considered. Forest owners are also characterized by their risk preferences but there is currently no estimation available for this parameter in the case of small forest owners. In reference to previous empirical studies, ${ }^{6}$ we considered the following value of $\beta=0.5$. This value is consistent with the range of reported estimates in the economic literature (see Eeckhoudt et al., 2005). It corresponds to a low level of risk aversion. This case will be referred to as the benchmark case in the rest of the article.

\footnotetext{
${ }^{5}$ During summer 2016, the French government proposed ten year government bonds at an interest rate between $0.1 \%$ and $0.2 \%$.

${ }^{6}$ Using an experimental approach, Brunette et al. (2014) found a relative risk aversion coefficient close to 1 . The value seems high and strongly depends on the approach.
} 


\section{Solution method}

\section{Independent model}

The solution of the independent model is obtained by solving the single MDP with sizes of the state and action state spaces equal to $m$ and 2, respectively. The problem is solved using the classical policy iteration algorithm (Howard, 1960). The optimization problem was solved numerically ${ }^{7}$ with MATLAB (2013) using the MDP toolbox (Chadès et al., 2014). The MDP toolbox offers a function based on the policy iteration algorithm to calculate the optimal policy. This function only requires that the problem be correctly described without necessarily stating any initial land allocation.

\section{Joint model}

Considering $n=$ five plots and combining the plot states (five possible states for each plot), we have 3125 possible system states: $S=\{1, \ldots, 3125\}$. Each system state $s$ corresponds to a set of five plot age classes $\left(s_{1}, \ldots, s_{5}\right)$. The states are designated in lexicographic order:

\begin{tabular}{llllll}
\hline$s$ & $\left(s_{1}\right.$ & $s_{2}$ & $s_{3}$ & $s_{4}$ & $\left.s_{5}\right)$ \\
\hline 1 & $(1$ & 1 & 1 & 1 & 1 \\
2 & $(1$ & 1 & 1 & 1 & $2)$ \\
3 & $(1$ & 1 & 1 & 1 & $3)$ \\
4 & $(1$ & 1 & 1 & 1 & $4)$ \\
5 & $(1$ & 1 & 1 & 2 & $5)$ \\
6 & $(1$ & 1 & 1 & 5 & $1)$ \\
1 & & 1 & 5 & 5 & $4)$ \\
3124 & $(5$ & 5 & 5 & $5)$ & 5 \\
3125 & $(5$ & 5 & & & 5
\end{tabular}

The set of actions $A$ is defined as $A=\{1, \ldots, 32\}$; each action $a$ corresponds to a set of plot actions $\left(a_{1}, \ldots, a_{5}\right)$. Actions are also designated in lexicographic order:

\begin{tabular}{llllll}
\hline$a$ & $\left(a_{1}\right.$ & $a_{2}$ & $a_{3}$ & $a_{4}$ & $\left.a_{5}\right)$ \\
\hline 1 & $(1$ & 1 & 1 & 1 & $1)$ \\
2 & $(1$ & 1 & 1 & 1 & $2)$ \\
3 & $(1$ & 1 & 1 & 2 & $1)$ \\
4 & $(1$ & 1 & 1 & 2 & $2)$ \\
1 & 1 & 2 & 2 & $2)$ \\
\hline
\end{tabular}

The global transition probability table is defined from Equation (1):

$$
p\left(s^{\prime} \mid s, a\right)=\sum_{\epsilon \in\{0,1\}} \prod_{i=1}^{n} p\left(s_{i}^{\prime} \mid s_{i}, a_{i}, \epsilon\right) p(\epsilon) .
$$

All individual transition tables $p$ are defined by:

1 If the action is "cut" $\left(a_{i}=2\right), p\left(1 \mid s_{i}, 2\right)=1$ and $p\left(s_{i}^{\prime}=2, \ldots, 5 \mid s_{i}, 2\right)=0, \forall i$,

\footnotetext{
${ }^{7}$ All the Matlab codes to run and to reproduce the study are available on the on-line repository FigShare at the following address: http://dx.doi.org/10.6084/m9.figshare.904851.
} 
2 if the action is "wait" $\left(a_{i}=1\right), p\left(s_{i}^{\prime} \mid s_{i}, a_{i}\right)$ is defined as $p\left(s_{i}^{\prime} \mid s_{i}, 1\right)=M\left(s_{i}, s_{i}^{\prime}\right)$ with matrix $M$ defined as $M=\left(1-p_{s}\right) \cdot P_{0}+p_{s} \cdot P_{1}$, where:

$$
P_{0}=\left(\begin{array}{ccccc}
0 & 1 & 0 & 0 & 0 \\
0 & 0 & 1 & 0 & 0 \\
0 & 0 & 0 & 1 & 0 \\
0 & 0 & 0 & 0 & 1 \\
0 & 0 & 0 & 0 & 1
\end{array}\right) \text { and } P_{1}=\left(\begin{array}{ccccc}
p d_{1} & 1-p d_{1} & 0 & 0 & 0 \\
p d_{2} & 0 & 1-p d_{2} & 0 & 0 \\
p d_{3} & 0 & 0 & 1-p d_{3} & 0 \\
p d_{4} & 0 & 0 & 0 & 1-p d_{4} \\
p d_{5} & 0 & 0 & 0 & 1-p d_{5}
\end{array}\right)
$$

The size of the global transition probability table $p$ is $3125 \times 3125 \times 32$. The problem can also be solved using the classical policy iteration algorithm and was solved numerically using the MDP toolbox.

However, using the above-defined MDP model, our computer server (two Intel Xeon E5-2690 processors, eight cores, 128 Go RAM) cannot solve problems with more than five stands due to the size of the generated transition table, $p$. Therefore, for larger problems, we developed an equivalent MDP model of the forest management problem, which uses a more concise (aggregated) representation of the states and action spaces and, therefore, a transition matrix and reward function. This second model is used in the larger experiments. It should be in fact noted that in the above state representation, where $s=\left(s_{1}, \ldots, s_{n}\right)$, with $s_{i} \in\{1, \ldots, m\}$, the state of each individual stand is not really relevant for the management problem since the stand characteristics are assumed to be identical: the only relationships between stands are through the global storm event and the reward aggregation function, and the stand indices can be interchanged without any problem in these relationships. Thus, the relevant information is the number of stands in each age class, which can be represented by the vector $s^{A}=\left(s_{1}^{A}, \ldots, s_{m}^{A}\right)$. Accordingly, the relevant action information is the number of stands cut in each age class, which can be represented by action vector $a^{A}=\left(a_{1}^{A}, \ldots, a_{m}^{A}\right)$. With this equivalent "aggregated" representation, both state space size and action space size can be considerably reduced. Furthermore, the complexity of finding an optimal policy in the aggregated model is less sensitive to the increase in the number of stands, $n$, than the initial model. It can be shown that the time needed to find an optimal policy roughly increases linearly with $n^{m}$, as opposed to $m^{n}$ in the initial model. ${ }^{8}$ In practice, with the aggregated model, our computer server is able to precisely solve problems with 12 stands and five age classes.

\section{Case study: results and discussion}

In this section, after presenting the optimal policy in the benchmark case, we investigate how windthrow probabilities and risk preferences impact the optimal forest owner decisions and the optimal long-run equilibrium ${ }^{9}$ of the expected forest age distribution.

\section{Optimal policy in the benchmark case}

We first focus on the optimal forest harvesting decisions in the benchmark case computed with the joint uneven-aged forest management model.

When the forest owner has five plots (the benchmark case), in the long-run equilibrium (Fig. 2a), the proportion of stands allocated to each age class 1-4 is still higher than that of the fifth age class (see Table 2): however, the latter proportion is strictly positive. Moreover, it becomes optimal to smooth the age class structure if the number of stands increases, and to eventually converge to a normal forest

\footnotetext{
${ }^{8}$ Since $\left|S^{A}\right|=C_{n}^{m}=(n ! / m !(n-m) !) \leq n^{m},\left|A^{A}\right| \leq n^{m}$ and classical MDP algorithms solve problems in $O\left(|S|^{2}|A|\right)=O\left(n^{3 m}\right)$, instead of $O\left(m^{n}\right)$.

${ }^{9}$ For example, to give an idea of computing time, obtaining the long-run equilibrium for the joint uneven-aged forest management model with our computer server takes about 3 hours.
} 


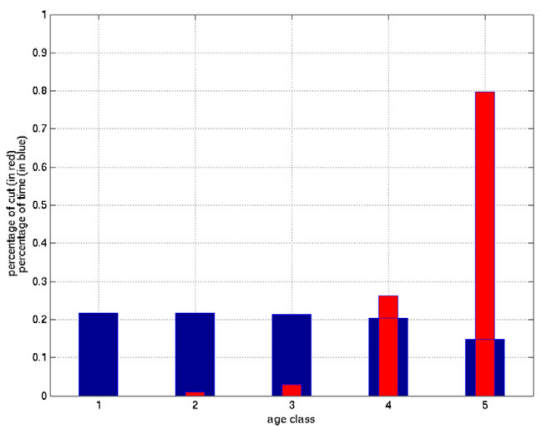

a) Joint model

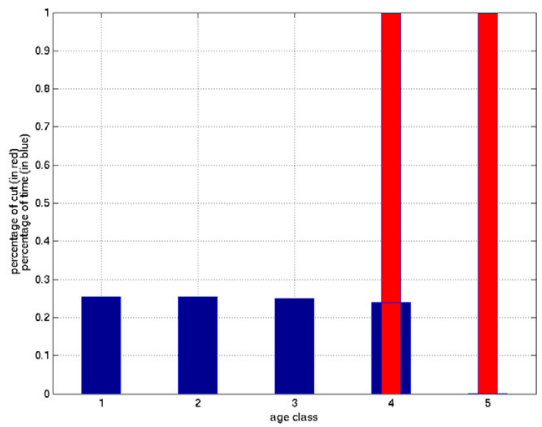

b) Independent model

Fig. 2. Optimal policies for the benchmark case with the joint uneven-aged forest management model and with the independent uneven-aged forest management model. The $x$-axis represents the age class and the $y$-axis represents the percentage of cut (in red) and the percentage of time spent by any stand in each age class (in blue). (For interpretation of the references to color in this figure legend, the reader is referred to the web version of this article.)

\section{Table 2}

Long-run equilibrium values of the areas dedicated to the different tree age classes, and certainty equivalents computed with the joint uneven-aged forest management model for one, five and 10 stands for an optimal policy.

\footnotetext{
Number of stands Percentage of time spent in each age classes ${ }^{a}$
}

\section{Certainty} equivalent for risk-averse policy per stand $\left(\pi_{\beta=0.5}^{*}\right)$

in $€$

\begin{tabular}{lllll}
\hline 1 & 3 & 4 & 5
\end{tabular}

\begin{tabular}{lllllll}
$\begin{array}{l}\text { Benchmark case } \\
\text { Five plots }\end{array}$ & 0.2175 & 0.2174 & 0.2132 & 0.2045 & 0.1474 & $9.45 \times 10^{6}$ \\
$\begin{array}{l}\text { Variation } \\
\text { Ten plots }\end{array}$ & 0.2125 & 0.2114 & 0.2074 & 0.1981 & 0.1707 & $9.50 \times 10^{6}$ \\
One plot & 0.2550 & 0.2549 & 0.2501 & 0.2400 & 0 & $1.96 \times 10^{6}$ \\
\hline
\end{tabular}

a These percentages can be interpreted in two strictly equivalent ways: (i) as the average (over stands) percentage of time spent by any stand in each age class or (ii) as the average (over time) percentage of the area of the forest in each age class.

structure where only the oldest tree age class is harvested. When stands are managed independently (since the latter case corresponds to five independently managed plots) or in the single stand case (the case of one plot in Table 2), the optimal forest management is different from the optimal one in the benchmark case: in the long-run equilibrium, the areas dedicated to age classes 1 to 4 are almost the same and the area allocated to the fifth age class is null. In this case, the optimal forest management does not tend toward a normal forest structure, but instead toward a restricted normal forest where the oldest age class is excluded from the forest structure but the principle of the normal forest is respected among the remaining age classes. In this case, the optimal policy is the following one: it is always optimal to harvest age class 4 , for a starting state of age less than 5 , and if the starting state is the age class 5 , then it is also optimal to harvest.

In the joint uneven-aged forest management model, the forest owner can manage risk by exposing the oldest age class to the windthrow risk, in order to obtain higher returns. The possibility of diversifying risks ${ }^{10}$ using the different plots allows the forest owner to harvest different age classes and to

\footnotetext{
10 In this case, the forest owner may obtain diversification gains due to the fact that stands may be considered as different assets; therefore, for the same level of risk, the return can be increased. This result is classical in the portfolio theory applied to forest management (see, for example: Reeves and Haight, 2000; Hyytiä inen and Penttinen, 2008; Hildebrandt and Knoke, 2011; Roessiger et al., 2011).
} 
dedicate some space to the oldest age class in order to converge to a normal forest, which is generally the case in the forest economics literature (see Salo and Tahvonen, 2002; Couture and Reynaud, 2007 among others). ${ }^{11}$ Contrary, in the independent uneven-aged forest management model, the forest owner limits the possibility of the stand to the first four age classes, never allowing the last age class, considered to be too risky. This result highlights the impact of jointly taking all of the plots in the optimal forest management policy into account. There is also an impact on the certainty equivalents ${ }^{12}$ of the expected present value for the optimal policy obtained for the risk averse forest owner $\left(\pi_{\beta=0.5}^{*}\right)$.

In Table 2, it can be observed that the certainty equivalent is higher when the forest manager can spread risk between several stands. This value ranges from $1.96 \times 10^{6}$ in the "independent" case, to $9.45 \times 10^{6}$ in the "jointly managed" case. This shows that an independent management of stands is suboptimal, compared to the optimal (joint) management. Thus, there is a real added-value when considering joint management policies in the case of storm risk.

\section{Assessment of the windthrow probability impact}

Climate change is associated with increased climate variability and, consequently, with an increased frequency of extreme events such as heat waves, severe droughts and intense storms. For the studied area, the trend of increased windthrow frequency remains vague, principally due to the lack of data and studies. Przyluski and Hallegatte (2012) conclude that no trend for an increase of the windthrow probability is demonstrated at the moment, while Develon (2002) has shown a trend of increasing storm numbers. However, it is still assumed that climate change and increased climate variability are expected to have repercussions on the windthrow probabilities. For forest owners, it is believed that adapting to climate change will require major adjustments in management practices. This is why we now investigate the impact of an increase in the windthrow probability on the long-run equilibrium in the MDP forest management model. We therefore consider that the impact of climate change is taken into account by solving different MDP with different storm probabilities. This is a common approach in the literature: the inclusion of climate change via a change in storm frequency seems relevant because future developments and their effects on forest ecosystems are not easily predicted or described in terms of standard probability concepts (Schou et al., 2015).

In addition to the initial value of the windthrow probability, we consider two other values $\left(p_{s}=0.068\right.$ and $p_{s}=0.093$ in a 20 -year period) that correspond to windthrow risk increased by $10 \%$ or $50 \%$, respectively. Such values correspond to very high values in the range of values predicted by experts. Fig. 3 shows that such variations in the windthrow probability (from the benchmark case) do not have much impact in terms of optimal policy and optimal forest structure. This can perhaps be explained by the still relatively small values considered for the windthrow probability. However, it is important to note that these values are larger than those generally proposed by climatologists' forecasts. This conclusion is also confirmed for the independent uneven-aged forest management model (see Fig. 4).

The certainty equivalents of optimal policies for the "realistic" storm probabilities are also shown in Table 3. We observe that even if the optimal policy remains unchanged, an increase in the probability of windthrow will result in a decrease in the expected present value of the optimal policy. Given that the optimal policy is unchanged, this result is very intuitive. The expected present value should decrease since a higher proportion of the timber is damaged by storm when the storm probability is increased.

\footnotetext{
11 When stand interactions are taken into account, for example, Meilby et al. (2001) showed that the effect of risk on optimal rotation age found in a single-stand model may substantially decrease. In the same way, Forsell et al. (2011) found that age rotations are slightly shortened on the average in the case where storm risk is considered, but that rotation ages may vary from stand to stand, depending on their location.

12 Although the optimal policies could be ranked directly using the expected utilities, it is preferable to calculate certainty equivalents since they are easier to intuitively interpret. The situation with the greatest certainty equivalent is most preferred.
} 

Probability of windthrow
equal to 0.062
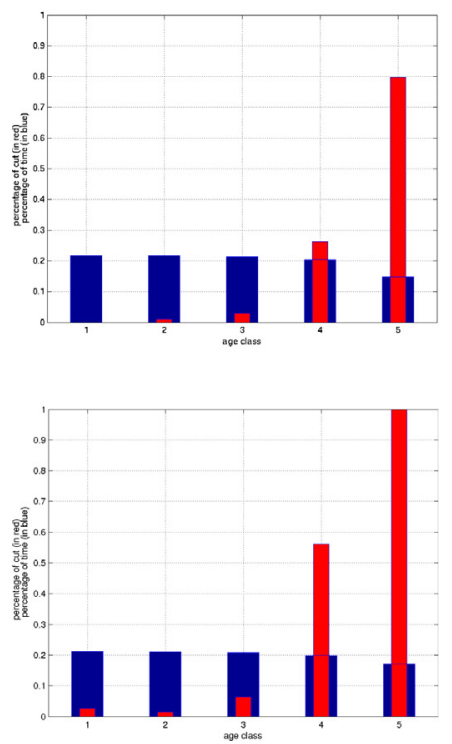

Probability of windthrow equal to 0.068

5 stands

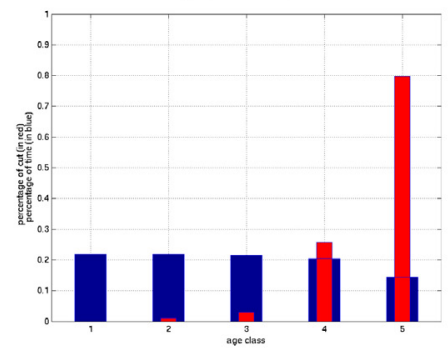

10 stands

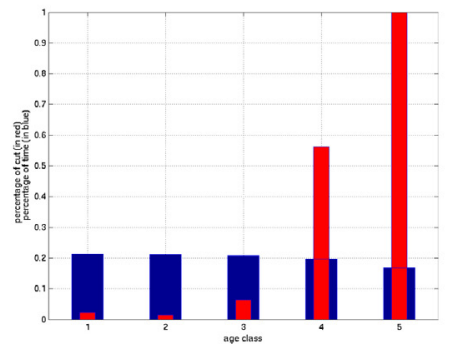

Probability of windthrow equal to 0.093

Fig. 3. Impact of the windthrow probability on the percentage of harvesting and on the percentage of time spent in each age class under the optimal policy for the joint uneven-aged forest management model for 5 and 10 stands. The $x$-axis represents the age class and the $y$-axis represents the percentage of cut (in red) and the percentage of time spent by any stand in each age class (in blue). (For interpretation of the references to color in this figure legend, the reader is referred to the web version of this article.)

Probability of windthrow equal to 0.062

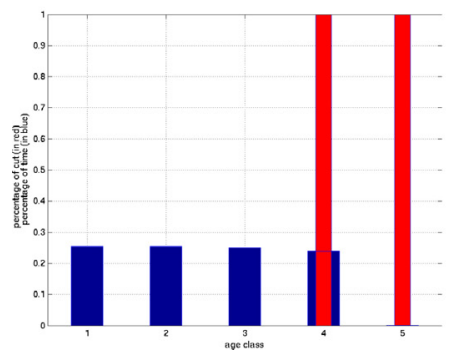

Probability of windthrow equal to 0.068

5 stands

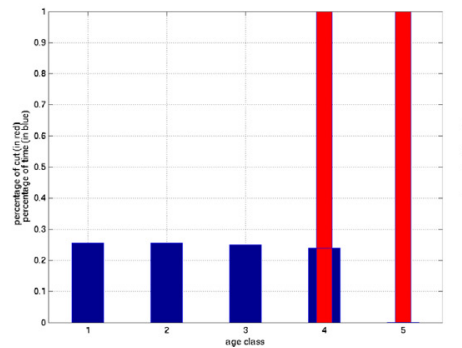

Probability of windthrow equal to 0.093

Fig. 4. Impact of the windthrow probability on the percentage of harvesting and on the percentage of time spent in each age class under the optimal policy for the independent uneven-aged forest management model for five stands. The $x$-axis represents the age class and the $y$-axis represents the percentage of cut (in red) and the percentage of time spent by any stand in each age class (in blue). (For interpretation of the references to color in this figure legend, the reader is referred to the web version of this article.)

\section{Assessment of the risk aversion impact}

First we analyze the impact of the risk aversion coefficient value on optimal policies and second we study the effect of the risk preference specification on optimal decisions. Finally we give some concluding remarks about the risk aversion impact. 
Table 3

Certainty equivalents for the different levels of windthrow probability with the joint uneven-aged forest management model for five stands and for 10 stands.

\begin{tabular}{llc}
\hline Probability of windthrow in a 20-year period & \multicolumn{1}{c}{$\begin{array}{c}\text { Certainty equivalents for risk averse policy per stand } \\
\text { (variation compared to the benchmark case) in } €\end{array}$} \\
\cline { 2 - 3 } & 5 stands & 10 stands \\
\hline$p_{s}=0.062$ (benchmark case) & $9.45 \times 10^{6}$ & $9.50 \times 10^{6}$ \\
$p_{s}=0.068$ & $9.31 \times 10^{6}(-1.48 \%)$ & $9.40 \times 10^{6}(-1.05 \%)$ \\
$p_{s}=0.093$ & $8.91 \times 10^{6}(-5.71 \%)$ & $8.93 \times 10^{6}(-6 \%)$ \\
\hline
\end{tabular}

The impact of the risk aversion coefficient value

We simulate the model for various levels of the Arrow-Pratt constant relative risk-aversion coefficient $(\beta)$, and we analyze the resulting optimal forest management policy. We measure the impact of varying the degree of risk aversion on the management strategy of a forest owner, and the longterm age profile of the forest. For this purpose, we consider two values for this coefficient, the first corresponding to a risk-neutral owner $(\beta=0)$ and the second consisting in an increase of risk aversion ( $\beta=0.9$, corresponding to a strongly risk-averse owner).

The forest age class profile remains relatively stable under this range of risk-aversion parameter values, but the management strategies change considerably (see Fig. 5). This complex behavior is difficult to explain at first glance. As Couture and Reynaud (2007) indicate, the behavior of a forest owner faced with a dynamic problem of forest management under risk depends on three effects. The first one, the wealth effect, corresponds to an incentive to harvest in order to increase the revenue resulting from timber harvesting. The second effect, the risk effect, makes the forest owner reduce the risk exposure of the forest and then to harvest in order to diminish future potential damage. The last effect, the continuation effect, is driven by the forest owner's tendency to reduce harvesting in order to smooth the utility over time. In light of these remarks, it can be observed that for risk-neutral or risk-averse owners, the more risk-averse the owner is, the more trees in intermediate age classes that will be cut. Consequently, the proportion of stands in the latest age class is decreased. However, this reduction is mitigated when the number of stand plots increases, and it becomes optimal to cut older age classes. Harvests are principally from the two oldest age classes, which are strongly harvested. It seems that in this case, the risk and wealth effects dominate.

With the independent uneven-aged forest management model, the impact of risk preferences on optimal policies differs (see Fig. 6). Optimal policies correspond to very simple threshold policies, and only the threshold changes. Risk-neutral managers only harvest the oldest trees. In this case, the structure of the forest converges toward a normal forest where only the oldest tree age class is harvested. When the level of risk aversion increases, the threshold decreases: At the limit, a strongly risk-averse manager $(\beta=0.9)$ is no longer ready to take any risk and, consequently, stands are cut during the first age class. Note that the difference between the independent uneven-aged forest management model and the joint uneven-aged forest management model is particularly sensitive to variations in the risk-aversion coefficient.

\section{The impact of the risk preference specification}

To complete this analysis, we now briefly investigate alternate specifications of the utility function. We consider two additional particular types of utility functions that are often encountered in the economics literature: a quadratic utility function and an exponential utility function, remembering that utility is unique only up to a linear transformation (Eeckhoudt et al., 2005).

Using the general definition of relative risk aversion, $\beta=-w\left(U^{\prime \prime}(w) / U^{\prime}(w)\right)$, we seek the parameters of a quadratic utility function and an exponential utility function for which the computed $\beta$ values are $0,0.5$ and 0.9 , like for the power utility function. We then compare the forms of the optimal policies and state occupation measures in the five stand model.

First, let us consider the classical quadratic utility function: $U(w)=a w-(1 / 2) w^{2}$, for which the expected utility criterion simplifies to a mean-variance approach. In this case, the relative risk aversion takes the form (computed through the general definition): $\beta=(w /(w-a))$. We can observe that (i) 

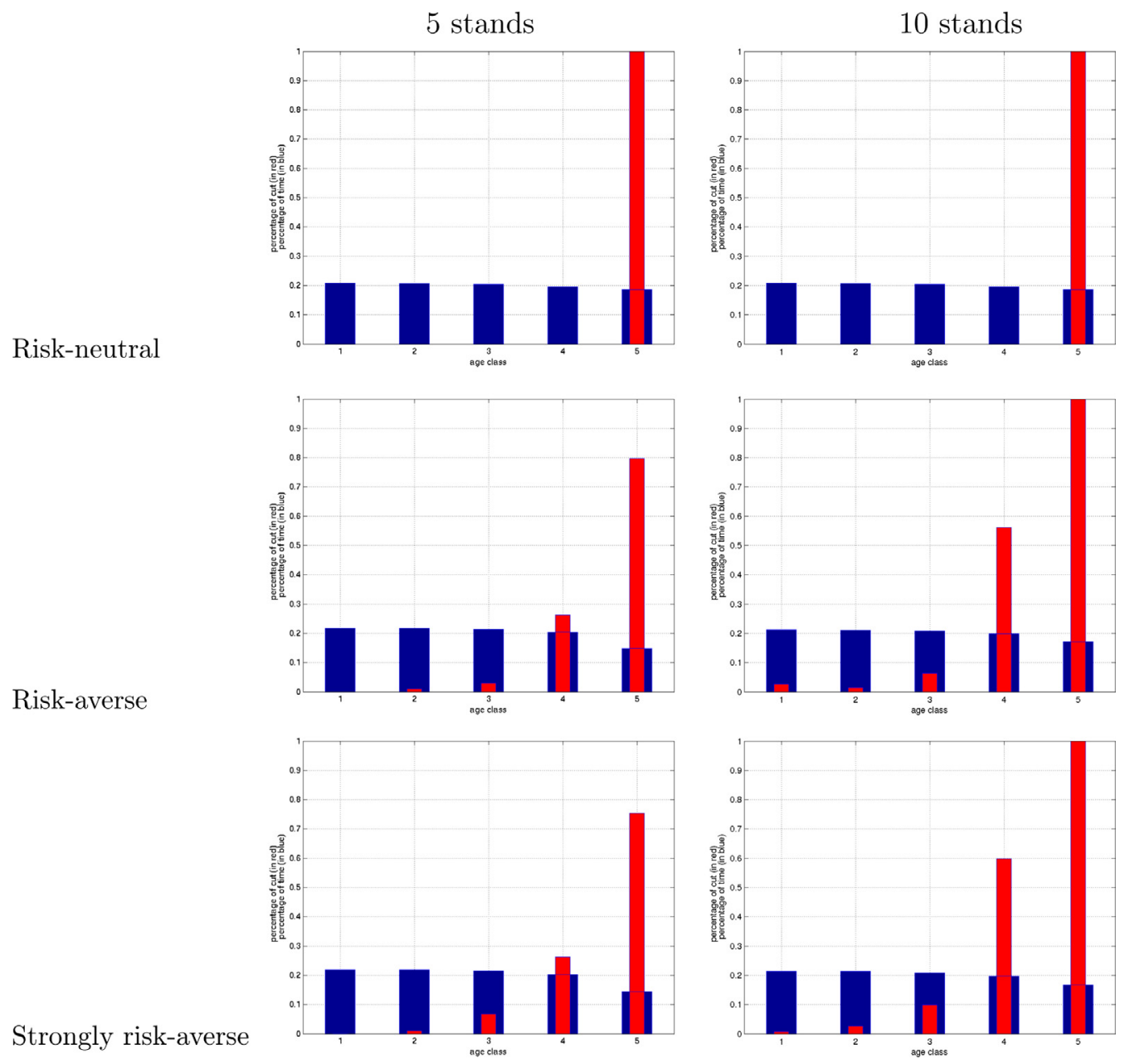

Fig. 5. Impact of the risk preference on the percentage of harvesting and on the percentage of time spent in each age class under the optimal policy for the joint uneven-aged forest management model. The $x$-axis represents the age class and the $y$-axis represents the percentage of cut (in red) and the percentage of time spent by any stand in each age class (in blue). (For interpretation of the references to color in this figure legend, the reader is referred to the web version of this article.)

unlike in the power function case, the relative risk aversion is not an explicit parameter and (ii) since the utility function should be non-decreasing, the level of revenue should be lower than parameter $a$. In order to be able to compare the quadratic utility case with the power utility case, we consider a risk aversion parameter $\bar{\beta}$ obtained by fixing the revenue to its empirical average, $\bar{w}$, over simulations of the optimal policy computed for the five stand case for the optimal policy (computed in the benchmark case). In practice, we obtain $\bar{w}=4927$. It can then be empirically observed that the maximum value of $w$ that can be reached is approximately 107,600, implying that $a>107,600$ in order to guarantee that the utility function is non-decreasing over the range of possible revenue levels. However, taking $\bar{w}=4927$ and $a>107,600$ in the quadratic utility function implies that $\bar{\beta} \leq 0.048$. This means that only a (quasi) risk-neutral attitude can be modeled using a quadratic utility in our case. Nevertheless, we compare the policy obtained with the quadratic utility and the risk-neutral policy obtained in the power utility function case in Fig. 7. These policies strongly differ, which, in addition to the fact 
Risk-neutral

$$
\beta=0
$$

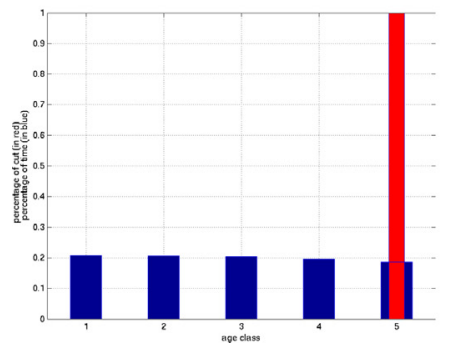

Risk-averse

$\beta=0.5$

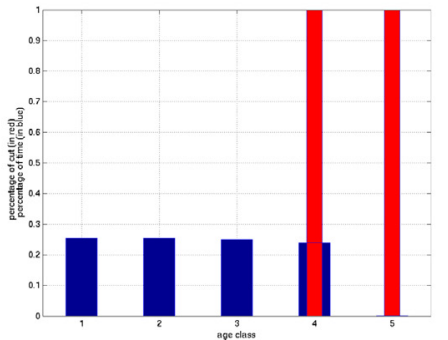

Strongly risk-averse $\beta=0.9$

Fig. 6. Impact of the risk preference on the percentage of harvesting and on the percentage of time spent in each age class under the optimal policy for the independent uneven-aged forest management model for five stands. The $x$-axis represents the age class and the $y$-axis represents the percentage of cut (in red) and the percentage of time spent by any stand in each age class (in blue). (For interpretation of the references to color in this figure legend, the reader is referred to the web version of this article.)

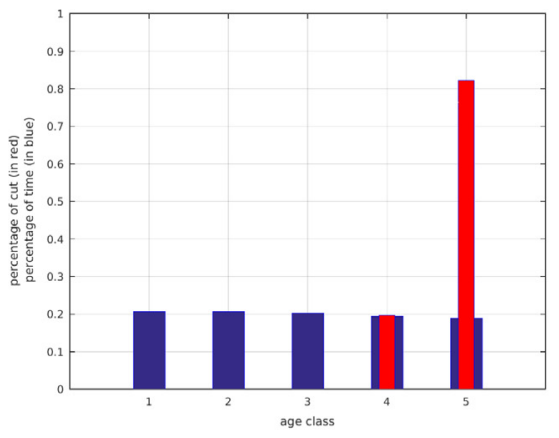

Quadratic utility function

$$
\beta=0.048
$$

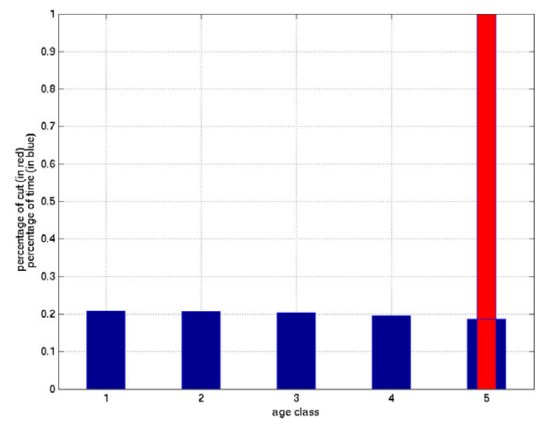

Power utility function

$$
\beta=0
$$

Fig. 7. Optimal policies for the quadratic utility function and the power utility function cases with the joint uneven-aged forest management model for five stands. The $x$-axis represents the age class and the $y$-axis represents the percentage of cut (in red) and the percentage of time spent by any stand in each age class (in blue). (For interpretation of the references to color in this figure legend, the reader is referred to the web version of this article.)

that large risk-aversion coefficients cannot be modeled, makes it a poor candidate for risk aversion modeling in our case.

A second set of classical utility functions is the class of the exponential utility functions. These functions have the form $U(w)=-(\exp (-a w) / a)$. Such functions are characterized by a constant absolute risk aversion $a$. This assumption eliminates the income effect, which is often criticized in the literature. The relative risk aversion coefficient in this case is $\beta=a w$. Fixing three values of $a$ so that $\bar{\beta}$ corresponds to the three levels $(\beta=0, \beta=0.5$ and $\beta=0.9$ ) for $\bar{w}=4927$ results in optimal policies that are represented in Fig. 8 for the five-stand case. We observe slight differences in this case. However, if we calculate the optimal policy for a level of absolute risk aversion coefficient equal to 0.5 we observe a strong impact (see Fig. 9) on optimal policies. These results highlight the importance of the income effect. It therefore appears to be important to consider a utility function that exhibits decreasing absolute risk aversion. 


$$
\begin{aligned}
& \beta=0 \\
& a=0
\end{aligned}
$$

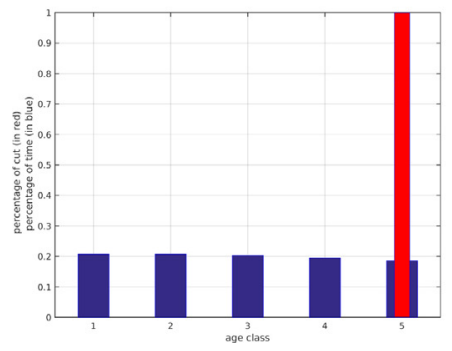

$\beta=0.5$

$a=0.00010148$

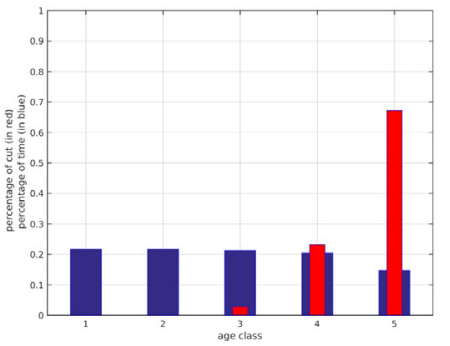

$\beta=0.9$

$a=0.00018267$

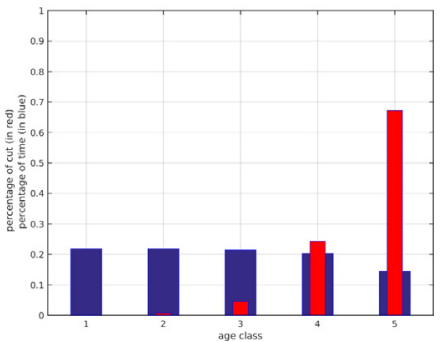

Fig. 8. Optimal policies for the exponential utility function case with the joint uneven-aged forest management model for five stands. The $x$-axis represents the age class and the $y$-axis represents the percentage of cut (in red) and the percentage of time spent by any stand in each age class (in blue). (For interpretation of the references to color in this figure legend, the reader is referred to the web version of this article.)

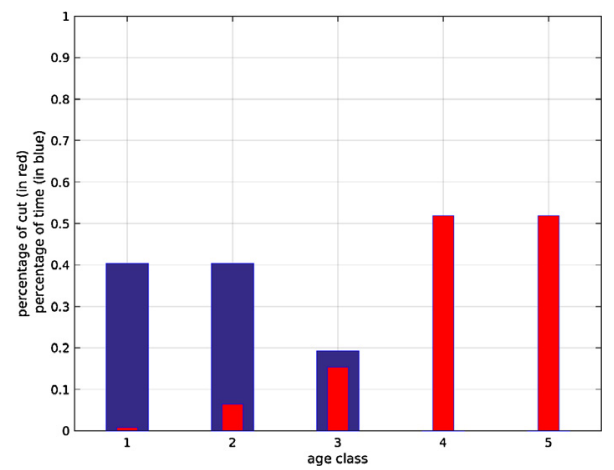

Fig. 9. Optimal policies for the exponential utility function case with the joint uneven-aged forest management model for five stands for a level of absolute risk aversion coefficient equal to 0.5 . The $x$-axis represents the age class and the $y$-axis represents the percentage of cut (in red) and the percentage of time spent by any stand in each age class (in blue). (For interpretation of the references to color in this figure legend, the reader is referred to the web version of this article.)

\section{Discussion}

The results of the analysis about the impact of risk aversion show, first, that the optimal management depends on risk preferences, and, second, the choice of utility function specification is crucial. Indeed, it is thus fundamental to incorporate the forest owner's risk aversion into forest management modeling. Furthermore, incorporating risk aversion also makes it important to use a joint model. The independent uneven-aged forest management model is not adapted to correctly represent the behavior of a risk-averse forest owner. Our results are in line with previous works that integrate risk aversion into forest management. They conclude that risk preferences have a strong impact on optimal forest policies (Couture and Reynaud, 2007, 2011; Andersson, 2012; Alvarez and Koskela, 2006). The additional result that we prove is that explicitly taking multiple stands into account in the model is necessary in order to better understand the effect of risk aversion in such a situation. Including risk attitudes in forest owners' decision management under uncertainty can help us to understand why non-industrial private forest owners' harvesting deviates from net present value maximization (Andersson, 2012). This calls for a deeper understanding of forest owners' risk preferences, as recently suggested by Andersson and Gong (2010). In the same way, the results of this analysis highlight the importance of specifying a utility function that exhibits decreasing absolute risk aversion in order to explicitly take into account the income effect. This is a very intuitive condition (as indicated by Arrow 
a/ For five stand plots

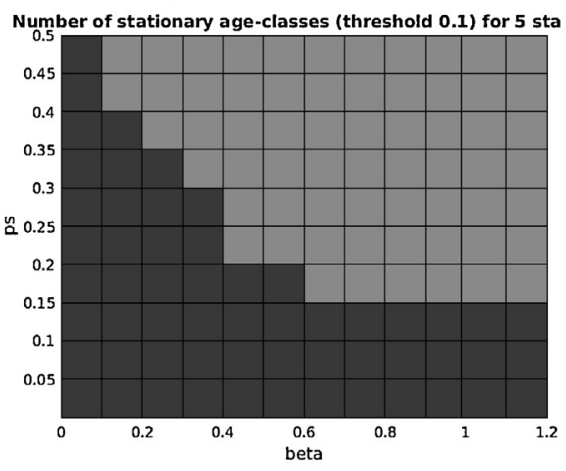

b/ For one stand plot

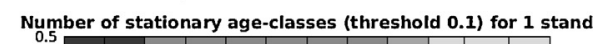

Number of stationary age-classes (threshold 0.1 ) for 1 stand

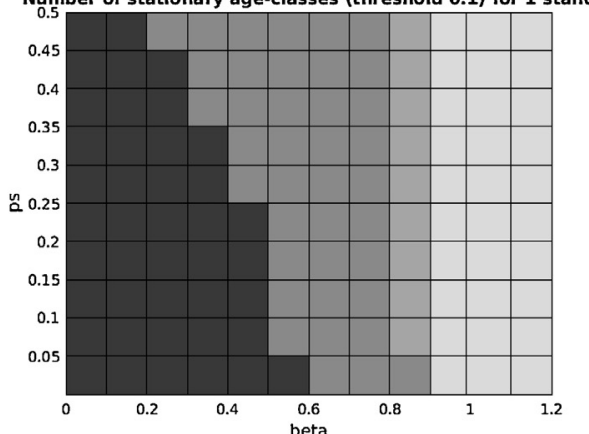

Number of age classes $\square: 5 \quad \square: 4 \quad \square: 3 \quad \square \quad 1$

Fig. 10. Optimal forest structure expressed in number of age classes where the forest is more than $10 \%$ of the time.

(1971)). Thus, to correctly describe the behavior of forest owners, the set of power utility functions seems to be the right choice for inferring risk aversion.

\section{Optimal structure of multi-stand settings}

In this subsection, we identify the optimal forest structure for a multi-stand forest depending on the level of risk and on the level of the forest owner's risk aversion. Since climate change results in an increase in the frequency of extreme climatic events, it is interesting to analyze how optimal forest owners' decisions are modified by changes in the risk of storm. This will result in unchanged optimal rotation for low levels of risk and shortened optimal rotation for high levels of windthrow risks, but will always smooth the age class structure. In the same way, including risk aversion changes the harvesting policy and also always smooths the structure of the forest. Independently increasing the forest owner's risk aversion or windthrow risk has the same effect of smoothing the structure of the forest. It is thus interesting to simultaneously analyze variations of both risk and risk aversion. This is the question we will now investigate. To achieve this goal, we define a frontier in the risk/risk aversion space that leads to a smooth forest structure and we show that the shape of this frontier is strongly affected by the number of stands.

Fig. ${ }^{13} 10$ a represents the risk/risk aversion frontier that maintains the convergence towards the optimal normal forest structure for the five-stand case. The darker gray region corresponds to couples (risk, risk aversion) in which it is optimal to smooth the age class structure (in this case, we assume that the percentage of time spent in the fifth age class is greater than $10 \%$ ) whereas the lighter gray region corresponds to situations in which the optimal forest structure is principally composed of four age classes. Up to the windthrow probability level of 0.15 , there is no effect on the forest structure, but for levels of risk higher than this threshold, the impact depends on the level of the forest owner's risk aversion. The oldest age class is excluded from the optimal structure for higher levels of risk aversion. The economic intuition of this result is straightforward. For a given level of risk, increasing the forest owner's risk aversion affects the optimal structure of the forest, excluding the most risky age class to limit the risk of storm damage.

It should be noted that if it is assumed that climate change will greatly increase the probability of windthrow occurrence, then forest owners will be induced to change their optimal forest structure despite risk aversion. This conclusion is important in terms of policy consequences. If a government

\footnotetext{
13 This figure is obtained with the MATLAB pcolor function that plots a rectangular array of cells whose colors are determined from the set of four adjacent point values.
} 
implements actions in order to reduce the probability or the potential damage of windthrow occurrence, then the final impact of such an action will strongly depend on forest owners' risk preferences. When the forest owner has only one plot (see Fig. 10b), the importance of the forest owners' risk preferences is also confirmed, and suggests that the optimal forest structure appears to be very sensitive to the level of risk aversion. Therefore, any model aiming to provide policy implications should carefully investigate the risk preferences of forest owners.

\section{Conclusion}

We used an MDP model with an expected utility criterion for analyzing the forestry decisions of a non-industrial private forest owner facing a windthrow risk due to climate change. The problem of the forest owner is to manage a forest composed of different stand plots with different age classes in the presence of windthrow risk. We designed optimal forest harvesting policies including multiple age classes and forest owners' risk aversion using an MDP framework. Our model generalizes existing MDP studies that assume a single stand and risk neutrality. We considered two management types: the joint uneven-aged forest management model in which the forest owner jointly manages all the different stand plots, and the independent uneven-aged forest management model that assumes that the forest owner independently manages each plot of the forest. We have applied this framework to the management of a French forest owner facing windthrow risk. In this context, we conducted sensitivity analyses on the effects of risk preferences and windthrow probabilities on the optimal policies.

The first and main finding of this study is to have shown the importance of an explicit multi-stand modeling of forest dynamics in terms of their management. We in fact found that optimal multistand management strategies differ from optimal independent management strategies. The expected present value per stand of forests is significantly higher under a multi-stand optimal management strategy than under an independent management strategy. When doing multi-stand management, forest owners use diversification among several stands instead of cutting age to protect themselves against risk, resulting in later harvest on average and more revenue. The analysis of the risk-preference impact on optimal management strategies is significantly altered when single-stand strategies are considered. The second finding concerns risk preference. We found that the sensitivity of the risk management to risk preference is rather complex. The age class profile is not significantly altered under optimal policies in different risk-preference conditions, whereas optimal management strategies strongly depend on the risk preference parameter value. Our second finding is still in the line of already existing works on risk preference. Our last finding concerns the impact of increased storm risk on forest management. We did not found a significant impact of an increased storm risk on the optimal forest management strategy, which could perhaps appears to be a bit counter-intuitive. However, even if the optimal strategies are rather insensitive to increased storm risk, the corresponding expected present value was found to be clearly sensitive to an increase in storm risk, as expected.

A challenge for future research is to propose a general model that would extend ours in three additional directions. First, forest owners can take prevention and coverage measures such as private insurance, self-insurance activity, self-protection actions or public funds against the potential losses of timber production due to climate change. Second, in the same way, it would be interesting to introduce consumption-saving decisions into the model in order to analyze the link between these decisions and forest management. Lastly, in a changing climate, higher risks caused by more extreme events will affect timber production as well as non timber forest products that are also sensitive to weather variability. It would be important to introduce the non timber benefits of the forest into the objective function A global model that encompasses ours, and these three extensions would be an important step for forest economics research.

\section{References}

Adams, D.M., Ek, A.R., 1974. Optimizing the management of uneven-aged forest stands. Can. J. Forest Res. 4 (3), $274-287$. Alanis-Duran, A., Cavazos-Cadena, R., 2012. An optimality system for finite average Markov decision chains under risk-aversion. Kybernetica 48 (1), 83-104. 
Alvarez, L.H.R., Koskela, E., 2006. Does risk aversion accelerate optimal forest rotation under uncertainty? J. Forest Econ. 12, 171-184.

Andersson, M., 2012. Assessing non-industrial private forest owners' attitudes to risk: do owner and property characteristics matter? J. Forest Econ. 18 (1), 3-13.

Andersson, M., Gong, P., 2010. Risk preferences, risk perceptions and timber harvest decisions - an empirical study of nonindustrial private forest owners in northern Sweden. Forest Policies Econ. 12 (5), 330-339.

Arrow, K.J., 1971. Essays in the Theory of Risk Bearing. Markham Publishing Co., Chicago.

Berck, P., 1979. The economics of timber: a renewable resource in the long-run. Bell J. Econ. 10, 447-462.

Boncina, A., 2011. History, current status and future prospects of uneven-aged forest management in the Dinaric region: an overview. Forestry 84 (5), 467-478.

Brunette, M., Couture, S., Laye, J., 2015. Optimizing forest management under storm risk with a Markov decision process model. J. Environ. Econ. Policy 4 (2), 141-163.

Brunette, M., Foncel, J., Kéré, E., 2014. Attitude Towards Risk and Production Decision: An Empirical Analysis on French Private Forest Owners. IUFRO World Congress, Salt Lake City.

Buongiorno, J., Zhou, M., 2011. Further generalization of Faustmann's formula for stochastic interest rates. J. Forest Econ. 17, $248-257$.

Chadès, I., Chapron, G., Cros, M.-J., Sabbadin, R., 2014. Mdptoolbox: a multi-platform toolbox to solve stochastic dynamic programming problems. Ecography 37, 916-920.

Coraluppi, S.P., Marcus, S.I., 1999. Stochastic analysis, control, optimization and applications, chapter risk-sensitive. In: McEneaney, W.M., et al. (Eds.), Minimax and Mixed Risk-Neutral/Minimax Control of Markov Decision Processes. Birkhauser, Boston.

Couture, S., Reynaud, A., 2007. Multi-stand forest management under a climatic risk: do time and risk preferences matter? Environ. Model. Assess. 13 (2), 181-193.

Couture, S., Reynaud, A., 2011. Forest management under fire risk when forest carbon sequestration has value. Ecol. Econ. 70 (11), 2002-2013.

Develon, C., 2002. L'évolution du nombre de tempêtes en france sur la période 1950-1999. La Météorologie 37, 46-56.

Dhote, J., 2000. Composition, structure et résistance des peuplements. In: Bergonzini, J.C., Laroussinie, O. (Eds.), Les écosystèmes forestiers dans la tempête. ECOFOR-MAP, Paris.

Eeckhoudt, L., Gollier, C., Schlesinger, H., 2005. Economic and Financial Decisions under Uncertainty. Princeton University Press.

FAO, 2013. Climate Change Guidelines for Forest Managers. FAO Forestry. Paper No. 172. Food and Agriculture Organization of the United Nations, Rome.

Forsell, N., Wikström, P., Garcia, F., Sabbadin, R., Blennow, K., Eriksson, L.O., 2011. Management of the risk of wind damage in forestry: a graph-based Markov decision process approach. Ann. Oper. Res. 190 (1), 57-74.

Goetz, R.U., Hritonenko, N., Mur, R., Xabadia, A., Yatsenko, Y., 2013. Climate change and the optimal management of sizedistributed forests under endogenous risk of fire. In: EAERE Annual Conference, Toulouse.

Gong, P., 1998. Risk preferences and adaptive harvest policies for even-aged stand management. Forest Sci. 44 (4), $496-506$.

Gong, P., Löfgren, K.G., 2003. Risk-aversion and the short-run supply of timber. Forest Sci. 49 (5), 647-656.

Guo, B., 1994. Recherche d'une sylviculture optimale à long terme pour les peuplements forestiers équiennes (Ph.D. dissertation). ENGREF, Nancy.

Haarsma, R.J., Hazeleger, W., Severijns, C., de Vries, H., Sterl, A., Bintanja, R., van Oldenborgh, G.J., van den Brink, H.W., 2013. More hurricanes to hit western Europe due to global warming. Geophys. Res. Lett. 40 (9), 1783-1788.

Hanewinkel, M., Hummel, S., Albrecht, A., 2011. Assessing natural hazards in forestry for risk management: a review. Eur. J. Forest Res. 130, 329-351.

Hanewinkel, M., Khun, T., Bugmann, H., Lanz, A., Brang, P., 2014. Vulnerability of uneven-aged forests to storm damage. Forestry 87, 525-534.

Hildebrandt, P., Knoke, T., 2011. Investment decisions under uncertainty - a methodological review on forest science studies. Forest Policy Econ. 13, 1-15.

Hool, J.N., 1966. A dynamic programming-Markov chain approach to forest production control. Forest Sci. Monogr. 12.

Howard, R.A., 1960. Dynamic Programming and Markov Processes. MIT Press, Cambridge.

Hyytiä inen, K., Penttinen, M., 2008. Applying portfolio optimizations to the harvesting decisions of non-industrial private forest owners. Forest Policy Econ. 10, 151-160.

Johansson, P., Löfgren, K., 1985. The Economics of Forestry and Natural Resources. Basil Blackwell, Oxford, UK.

Kao, C., 1982. Optimal stocking levels and rotation under risk. Forest Sci. 28, 711-719.

Kaya, I., Buongiorno, J., 1987. Economic harvesting of uneven-aged northern hardwood stands under risk: a Markovian decision model. Forest Sci. 35 (33), 889-907.

Lembersky, M.R., Johnson, K.N., 1975. Optimal policies for managed stands: an infinite horizon Markov decision process approach. Forest Sci. 21 (2), 109-122.

Lin, C., Buongiorno, J., 1998. Tree diversity, landscape diversity, and economics of maple-birch forests: implications of Markov models. Manage. Sci. 44 (10), 1351-1366.

Lohmander, P., 2011. Adaptative optimization of forest management in a stochastic world. In: Weintraub, A., Bjorndal, T., Epstein, R., Romero, C. (Eds.), Handbook of Operations Research in Natural Resources. Springer, Berlin.

Loisel, P., 2014. Impact of storm risk on Faustmann rotation. Forest Policy Econ. 38, 191-198.

Lönnstedt, L., Svensson, J., 2000. Non-industrial private forest owner's risk preferences. Scand. J. Forest Res. 15 (6), $651-660$.

Lyon, K., Sedjo, R., 1983. An optimal control theory model to estimate the regional long run timber supply. Forest Sci. 29, 798-812.

Mason, W.L., 2002. Are irregular stands more windfirm. Forestry 75, 347-355.

MATLAB, 2013. Version 8.1 (R2013a). The MathWorks Inc., Natick, MA.

Meilby, H., Strange, N., Thorsen, B.J., 2001. Optimal spatial harvest planning under risk of wind throw. Forest Ecol. Manage. 149, $15-31$.

Mitra, T., Wan, H.Y., 1985. Some theoretical results on the economics of forestry. Rev. Econ. Stud. 52, $263-282$. 
O’Hara, K.L., Hasenauer, H., Kindermann, G., 2007. Sustainability in multi-aged stands: an analysis of long-term plenter systems. Forestry $80(2), 163-181$.

Ollikainen, M., 1993. A mean-variance approach to short-term timber selling and forest taxation under multiple sources of uncertainty. Can. J. Forest Res. 20, 1823-1829.

Pasalodos-Tato, M., Garcia-Gonzalo, J., Mäkinen, A., Borges, J.G., Lämås, T., Eriksson, L.O., 2013. Assessing uncertainty and risk in forest planning and decision support systems: review of classical methods and introduction of innovative approach. Forest Syst. 22 (2), 282-303.

Pastor, J., Sharp, A., Wolter, P., 2005. An application of Markov models to the dynamics of Minnesota's forests. Can. J. Forest Res. 35, 3011-3019.

Picard, O., Robert, N., Toppan, E., 2002. Les systèmes d’assurance en forêt et les progrès possibles. Rapport IDF.

Przyluski, V., Hallegatte, S., 2012. Gestion des risques naturels; leçons de la tempête Xynthia. Editions Quae, collection Matière à débattre et à décider, Versailles, $264 \mathrm{pp}$.

Puettmann, K.J., Wilson, S.McG., Baker, S.C., Donoso, P.J., Drössler, L., Amente, G., Harvey, B.D., Knoke, T., Lu, Y., Nocentini, S., Putz, F.E., Yoshida, T., Bauhus, J., 2015. Silvicultural alternatives to conventional even-aged forest management - what limits global adoption? Forestry 2 (8), 1-16.

Puterman, M.L., 1994. Markov Decision Processes. John Wiley and Sons, New York.

Reeves, L.H., Haight, R.G., 2000. Timber harvest scheduling with price uncertainty using Markowitz portfolio optimization. Ann. Oper. Res. 95, 229-250.

Roessiger, J., Griess, V.C., Knoke, T., 2011. May risk aversion lead to near-natural forestry? A simulation study. Forestry 84 , 527-537.

Rollin, F., Buongiorno, J., Zhou, M., Peyron, J.L., 2005. Management of mixed species, uneven-aged forests in the French Jura: from stochastic growth and price models to decision tables. Forest Sci. 51 (1), 64-75.

Ruszczynski, A., 2010. Risk-averse dynamic programming for Markov decision processes. Math. Program. Ser. B 125, $235-261$.

Sabbadin, R., Spring, D.A., Rabier, C.E., 2007. Dynamic reserve site selection under contagion risk of deforestation. Ecol. Modell. 201, 75-81.

Salo, S., Tahvonen, O., 2002. On the optimality of a normal forest with multiple land classes. Forest Sci. 48, 530-542.

Salo, S., Tahvonen, O., 2003. On the economics of forest vintages. J. Econ. Dyn. Control 27 (8), 1411-1435.

Salo, S., Tahvonen, O., 2004. Renewable resources with endogenous age classes and allocation of land. Am. J. Agric. Econ. 86 (2), 513-530.

Schelhaas, M.J., Nabuurs, G.J.L., Schuck, A., 2003. Natural disturbances in the European forests in the 19th and 20th centuries. Glob. Change Biol. 9, 1620-1633.

Schou, E., Thorsen, B.J., Jacobsen, J.B., 2015. Regeneration decisions in forestry under climate change related uncertainties and risks: effects of three different aspects of uncertainty. Forest Policy Econ. 50, 11-19.

Sedjo, R., Lyon, K., 1990. The Long-Term Adequacy of World Timber Supply. Report. Resources for the Future RFF, Washington, DC.

Sigaud, O., Buffet, O., 2010. Markov Decision Processes in Artificial Intelligence. John Wiley \& Sons, Inc., Hoboken, NJ. USA.

Spring, D.A., Kennedy, J.O.S., Nally, R.M., 2005a. Optimal management of a forested catchment providing timber and carbon sequestration benefits: climate change effects. Glob. Environ. Change 15 (3), 281-292.

Tahvonen, O., 2004. Optimal harvesting of forest age classes: a survey of some recent results. Math. Popul. Stud. 11, $205-232$.

Tahvonen, O., Kallio, M., 2006. Optimal harvesting of forest age classes under price uncertainty and risk aversion. Nat. Res. Model. 19 (4), 557-585.

Teeter, L.D., Caulfield, J.P., 1991. Stand density management strategies under risk: effects of stochastic prices. Can. J. Forest Res. 21, 1373-1379.

Vannière, B., 1984. Tables de production pour les forêts françaises. E.N.G.R.E.F Press, Nancy.

Williams, B.K., 2009. Markov decision processes in natural resources management: observability and uncertainty. Ecol. Modell. $220,830-840$

Yousefpour, R., Jacobsen, J.B., Thorsen, B.J., Meilby, H., Hanewinkel, M., Oehler, K., 2012. A review of decision-making approaches to handle uncertainty and risk in adaptative forest management under climate change. Ann. Forest Sci. 69, 1-15.

Zhou, M., Buongiorno, J., 2011. Effects of stochastic interest rates in decision making under risk: a Markov decision process model for forest management. Forest Policy Econ. 13, 402-410. 